\title{
Multilinear regression analysis on solid waste generation quantity in Malaysia towards sustainable development
}

\author{
Faridah Zulkipli ${ }^{1}$ *, Zulkifli Mohd Nopiah ${ }^{2}$, Noor Ezlin Ahmad Basri ${ }^{2}$, Cheng Jack Kie ${ }^{3}$, Siti Sarah Januri ${ }^{4}$ \\ ${ }^{1}$ Faculty of Computer and Mathematical Sciences, Universiti Teknologi MARA, Perak Branch, Tapah Campus, 35400 Tapah Road, \\ Perak, Malaysia \\ ${ }^{2}$ Faculty of Engineering and Built Environment, Universiti Kebangsaan Malaysia, 39000 UKM Bangi, Selangor, Malaysia \\ ${ }^{3}$ Faculty of Industrial Management, Universiti Malaysia Pahang, Lebuhraya Tun Razak, 26300 Gambang, Kuantan, Pahang, \\ Malaysia \\ ${ }^{4}$ Faculty of Computer and Mathematical Sciences, Universiti Teknologi MARA (Kampus Seremban 3), 73600 Seremban, Negeri \\ Sembilan, Malaysia
}

\section{A R T I C L E I N F O}

\section{Article history:}

Received 28 April 2017

Received in revised form

27 July 2017

Accepted 30 July 2017

\section{Keywords:}

Solid waste generation

Solid waste management

Sustainable development

Correlation analysis

Multilinear regression analysis

\begin{abstract}
A B S T R A C T
Inadequate data will affect the efficiency of future planning of solid waste management in order to achieve sustainable development. The purpose of this paper is to investigate the effect of a number of factors, namely GDP, Demand of electricity, Population and Number of Employment, which could be applied to predict the solid waste generation quantities and improve the management of future planning. The data were statistically analyzed by conducting a bivariate analysis and multilinear regression analysis. The results revealed that the GDP, Demand of electricity, Population and Number of Employment reflects the prediction of sustainable solid waste generation. It was found that addition of all predictor variables accounted for 98.9 percent $(r=0.989)$ changes in the variance in the quantity of solid waste generation. Consequently, the department of solid waste can increase its effectiveness and efficiency in management through the prediction of the quantity of solid waste generation.
\end{abstract}

(C) 2017 The Authors. Published by IASE. This is an open access article under the CC BY-NC-ND license (http://creativecommons.org/licenses/by-nc-nd/4.0/).

\section{Introduction}

Waste can be defined as unwanted materials which consist of the unwanted materials left over from community or household activities, from industrial process and from agricultural operations. The material may be discarded, accumulated, stored or treated before being disposed and recycled. In recent years, waste has been a problem for many environment impacts of waste pollution. The quantity of solid waste increases rapidly due to increases in economic development, urbanization process and national population (Agamuthu et al., 2009; Badgie et al., 2012; Alias et al., 2014). Moreover, urbanization and waste generation are on-going processes, and the development of the environmental, economic, and social aspects of the country affect them interdependently. Therefore, we can say that the process of urbanization has generally increased the citizens' standard of living

\footnotetext{
* Corresponding Author.

Email Address: faridahzul@tmsk.uitm.edu.my(F. Zulkipli) https://doi.org/10.21833/ijaas.2017.09.006

2313-626X/C) 2017 The Authors. Published by IASE.

This is an open access article under the CC BY-NC-ND license

(http://creativecommons.org/licenses/by-nc-nd/4.0/)
}

and also triggered waste generation (Chua et al., 2011). This increase trend created a critical scenario for the management of solid waste. The use of different strategies has been put in place to solve the problem.

It is a more serious condition to be considered in developing countries rather than in developed countries. Developed countries have more sophisticated and systematic ways to handle solid waste management, with advanced technology and full participation from the public, stakeholders, policy makers, and government. In contrast, developing countries faced with lack of systematic approach, insufficient technology, and have less skilled workers for handling matters, as well as less awareness from other parties, such as the public (Budhiarta et al., 2012; Ahsan et al., 2014).

The main strategy of solid waste management is to address public health, be environment friendly, optimise utilisation of land and resources, and also address the economic concerns which are associated with improper waste management (Marshall and Farahbakhsh, 2013). Sustainable development in solid waste management is needed to cover all the three factors, which are the environment, the economy and the society. The goal is to achieve 
sustainable fulfilment through equally balanced components. The management process should highlight the importance of its assessment on the environment, society, and economy. This helps a country like Malaysia to portray itself as a developing country that is moving towards achieving sustainable development.

A sustainable waste management system is a planning and design model that contributes to increasing the efficiency in the use of natural resources and in decreasing environmental burdens. In order to be sustainable, the waste management system should also be affordable and widely accepted by the public, as well as by key companies and organisations (Oriola, 2014).

\section{Solid waste management in Malaysia}

Waste minimization is the aim for Malaysian solid waste management. This aim ensures a sustainable environment for current and future generations. To achieve the fully-developed national target by 2020 , Malaysia should stress on the implementation of sustainable practices by giving more priority to the reduction and prevention of waste rather than its treatment and disposal in the hierarchy of waste management (Mallak et al., 2014). Solving waste management problems and finding suitable solutions to those problems are essential to recognising the limitations faced when executing waste minimization practices. Waste minimization practices are often affected by the lack of environmental awareness and perception. The lack of expertise in providing technological knowledge makes the situation worse (Agamuthu et al., 2007; EA, 2009). According to the MHLG (2006) report, the awareness issues needed serious act and attention.

The following Fig. 1, as mentioned in Begum et al. (2007), illustrates the waste minimization components. According to the figure, the two main practices in waste minimization fulfilment are waste reduction at the source and recycling of waste.

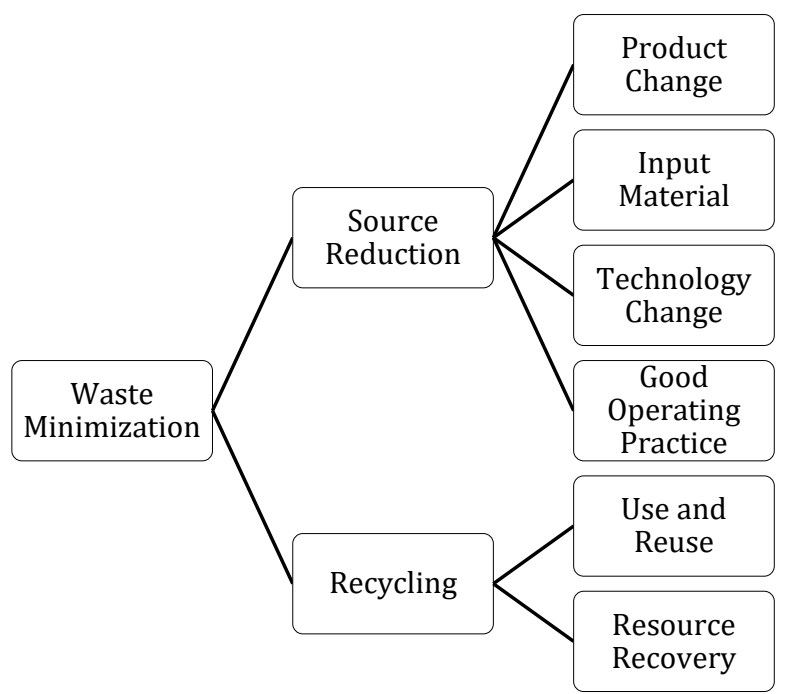

Fig. 1: Waste minimization conceptual framework

The use of waste minimization applications by industries in Malaysia is not a common practice.
However, only a small number of industries are incorporating the waste minimization concept as one of the fundamentals in their hierarchy of waste management. Thus, this small number of participation is too low to effectively decrease the total quantity of waste generation (Mallak et al, 2014; MHLG, 2014).

The rank waste hierarchy with waste management options according the best decision for the environment groups as a guiding principle for waste policy and program. This specifically gives top priority to prevent generated of waste in the first place. It gives priority to prepare it for reuse, recycle, compost, incinerate and final disposal.

Waste management hierarchy is commonly similar from country to one another. However, the strategy and the degree of application which is included in each country's environmental policies, depend on each strategic view and target. Fig. 2 in Agamuthu et al. (2009) compares the current and the targeted condition of the waste management hierarchy.

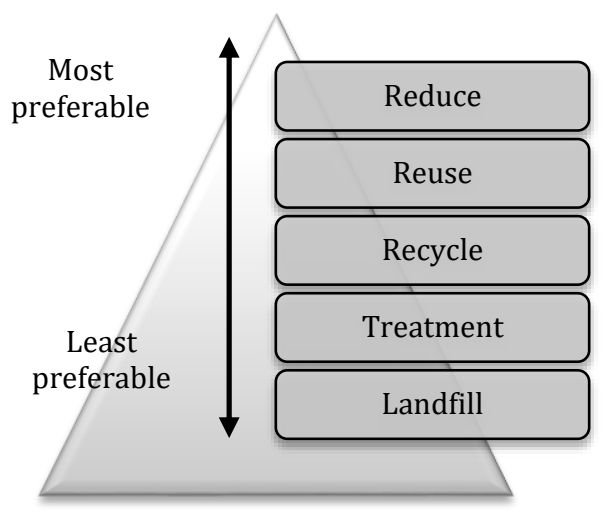

Fig. 2: Waste hierarchy

Malaysia Vision 2020 indicates that the planned solid waste disposal scenarios of the total solid waste generated (Younes et al., 2015). As in Table 1, reported by Agamuthu et al. (2009) that the target are recycling $(22 \%)$, composting $(8 \%)$, incineration (16.3\%), inert landfill (9.1\%), and sanitary landfill (44.1\%). Around $14 \%$ of them are utilised for the recycling of municipal, commercial, and industrial wastes, and $30 \%$ for the recycling of construction wastes. The solid waste composition and average density is equal to $770 \mathrm{~kg} / \mathrm{m}^{3}$.

Table 1: Percentages of waste disposed

\begin{tabular}{cccc}
\hline & \multicolumn{3}{c}{ Percentage of waste disposed (\%) } \\
\hline Alternatives & 2002 & 2006 & 2020 \\
Recycling & 5.00 & 5.50 & 22.00 \\
Composting & 0.00 & 1.00 & 8.00 \\
Incineration & 0.00 & 0.00 & 16.80 \\
Inert Landfill & 0.00 & 3.20 & 9.10 \\
Sanitary Landfill & 5.00 & 30.90 & 44.10 \\
Others Disposal & 90.00 & 59.40 & 0.00 \\
\hline
\end{tabular}

Solid waste generation in Malaysia exceeds nearly 30,000 tons per day, where more than $50 \%$ of it is through the open dumping disposal method and the recycling rate is of a relatively low percentage. The technological landfills (sanitary landfill and inert 
landfill) are gaining more attention by their management of solid waste. In Malaysia, the implementation of the 3Rs Plan (reuse, reduce, and recycle) to minimise the waste quantities is operationally not effective enough because of some barriers (Mohamad and Keng, 2013; Pariatamby and Fauziah, 2014). For example, lack of awareness, inappropriate packaging, lack of knowledge and information, lack of time, outdated technologies, and the incapability of organised governance and financial factors being implemented are the prevalent obstacles to the practice of waste minimisation by industrial divisions (EA, 2009; Pariatamby and Fauziah, 2014).

A study by Budhiarta et al. (2012), which conducted an investigation on the municipal solid waste composition in Kuala Lumpur City indicates that food waste $(44.5 \%)$ is the highest contributor to the municipal solid waste composition, followed by plastics (13.2\%) and diapers (12.1\%), as depicted in Fig. 3.

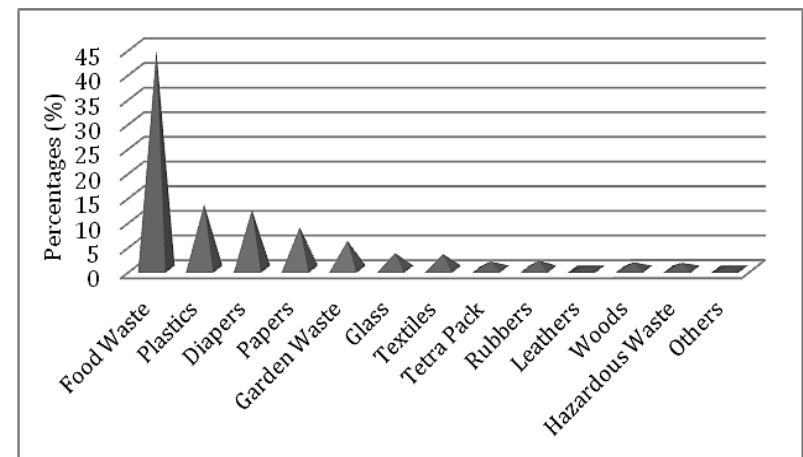

Fig. 3: Municipal solid waste composition in Kuala Lumpur

The planning and design of municipal solid waste management systems require accurate forecasting of solid waste generation. Nevertheless, accomplishing the anticipated prediction accuracy with regards to the generational trends faced by many fast-growing areas is pretty challenging. However, lack of complete historical records of solid waste measurements in quantity and quality due to inadequate budget and unavailable organisational capacity has given rise to a situation that renders the long-term system planning and short-term expansion programs intangible.

Moreover, due to limited data, lack of basic information, inappropriate methods of collecting data, industrial waste generation and composition, and clashes in definition of solid waste are among the fundamental obstacles for the appropriate planning of waste management (MHLG, 2006; 2014). Therefore, the hurdles in practicing waste minimisation in Malaysia are the same as some other countries.

Many researchers applied forecasting techniques for predicting the quantity of solid waste generation. Regression analysis has been chosen as a statistical tool to predict the solid waste generation quantity (Chung, 2010; Thanh et al., 2010; Andersen and Larsen, 2012). Some researchers established various relationships among socioeconomic factors and demographic factors in order to predict the solid waste generation quantity. These factors for example are population, income, GDP. Thus, the purpose of this study is to predict the waste generation in Malaysia towards sustainable development using multilinear regression analysis. The prediction of solid waste generation quantity will be used as a basic input for developing dynamical solid waste management strategy and planning.

\section{Methodology}

To the extent that the solid waste management is concerned, the prediction of waste generation plays a significant role. In the process of waste management planning, a perpetual reliable data is necessary when predicting the waste generation as mentioned in Ghinea et al. (2016). In the forecasting method, counts are frequently based on the demographic and socioeconomic factors on a per capita basis.

The methodology section is divided into three sub-sections. Sub-section 3.1, illustrate the proposed conceptual framework. Sub-section 3.2, present the bivariate analysis which is correlation analysis. This analysis is carried out in order to examine the strength of relationship between independent variables and dependent variable. Sub-section 3.3 performs a multilinear regression analysis to predict the future solid waste generation quantity. The SPSS software is used for performing the analysis.

\subsection{Proposed conceptual framework}

A basic step of correlation analysis and multilinear regression model are demonstrated in Fig. 4. First, retrieve collection of baseline data. Data set were collected from the Department of Solid Waste and the Department of Statistics Malaysia for the year 1981 to 2011, respectively.

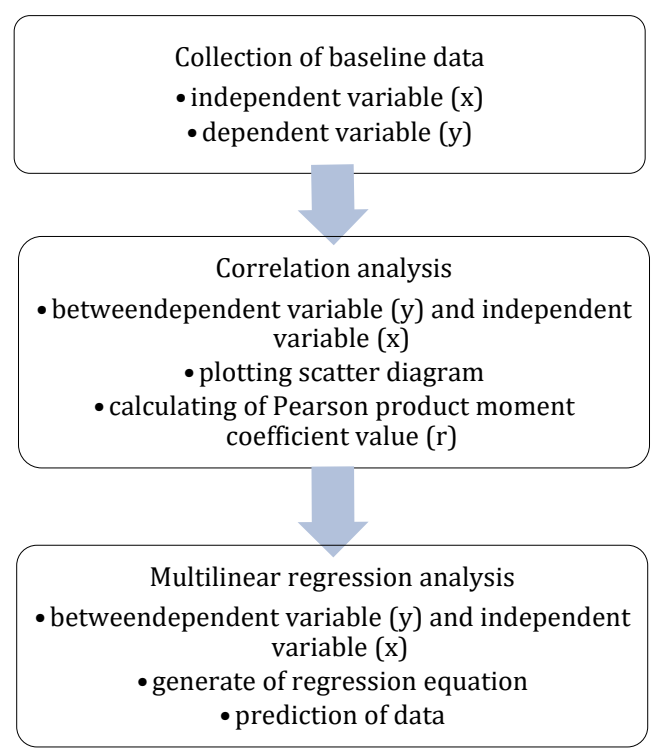

Fig. 4: Proposed conceptual framework

As in Fig. 5, it involves annual solid waste generation (kg/capita.year) as a dependent variable, 
and as an independent variables consists of GDP RM per capita (Beigl et al, 2004), population (*1000b), demand of electricity (kWh/capita) and the number of employment. Second, perform a correlation analysis. Third, conduct a multilinear regression analysis.

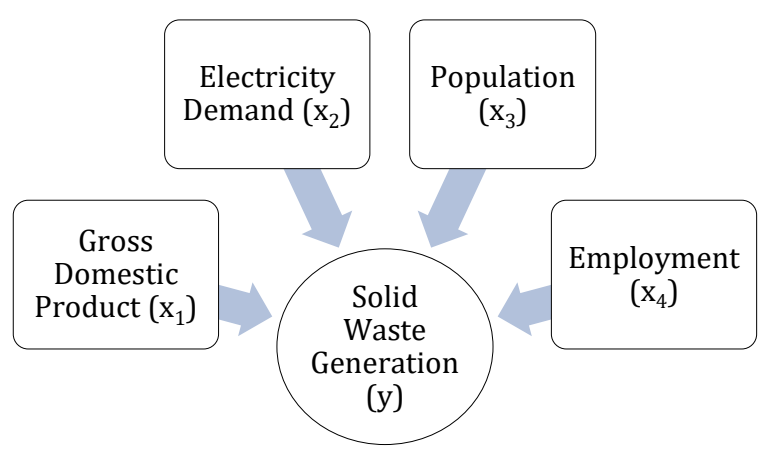

Fig. 5: Independent variables and dependent variable

\subsection{Bivariate analysis}

In the study, correlation analysis (bivariate analysis) is conducted in order to find the relationships between the two variables. Correlation analysis is a statistical method used to measure the strength of the relationship between independent variable $(\mathrm{x})$ and dependent variable $(\mathrm{y})$. The Pearson's product moment coefficient of correlation (r) as below is using for correlation analysis (Eq. 1).

$r=\frac{N\left(\sum x y\right)-\left(\sum x\right)\left(\sum y\right)}{\sqrt{\left[N \sum x^{2}-\left(\sum x\right)^{2}\right]\left[N \sum y^{2}-\left(\sum y\right)^{2}\right]}}$

Where $N$ is number of pairs of scores, $\sum x y$ is sum of the products of paired scores, $\sum x$ is sum of $x$ scores, $\sum y$ is sum of $y$ scores, $\sum x^{2}$ is sum of squared $x$ scores, $\sum y^{2}$ is sum of squared $y$ scores and the value of $r$ ranges from -1 to $1(-1 \leq r \leq 1)$.

\subsection{Multilinear regression analysis}

Multilinear regression analysis was used for developing a model to predict the quantity of solid waste generation in Malaysia. It is a statistical tool for analysing the relationship between dependent variable and many independent variables. Multilinear regression model attempts to establish the relationship between two or more independent variables and a dependent variable by fitting a linear equation to observed data. In every value of the independent variable $(\mathrm{x})$ is associated with a value of the dependent variable (y) and a basic multilinear regression model is presented as follows (Eq. 2):

$y_{i}=b_{o i}+b_{1 i} x_{1}+b_{2 i} x_{2}+b_{n i} x_{n}+. .+b_{n i} x_{n 1}+\varepsilon_{i}$ where $y_{i}$ is the dependent variable, $x_{1}, x_{2}, \ldots, x_{n}$ are the independent variables, $\varepsilon_{i}$ is the residual term and $b_{0 i}, b_{1 i}, b_{2 i}, \ldots, b_{n i}$ are the regression coefficients. Assumptions of multilinear regression are:

a. All variables are normally distributed

b. All independent variables are linear correlated

c. No multicollinearity exist

$\mathrm{d}$. There is no outlier exist in dependent variable

\section{Results and discussions}

\subsection{Analysis trend on dependent variable and independent variables}

Summary of descriptive statistics of the collected raw data is presented in Table 2. In this study, Figs. 6-9 illustrates increasing trends of waste generation quantity towards GDP, Demand of Electricity, Population and Number of Employment from 1981 to 2010 in Malaysia. The population progressively is increase by $2 \%$ - $3 \%$ annually. The waste generation quantities also steadily rise according to an increment of population. The gross domestic product shows a slight decline in between 1996-1997 and 2008-2009 which due to world economic crisis. In addition, the demand of electricity and the number of employment are rise continuously over time. Therefore, as a conclusion, the waste generation also increase over the decades because of the significant influence by all the factors.

\subsection{Results of bivariate analysis}

Population and gross domestic product can explain the quantity of waste generation. Table 3 shows the results on correlation analysis. As a result, all factors: $\operatorname{GDP}\left(\mathrm{x}_{1}\right)$, Demand of Electricity $\left(\mathrm{x}_{2}\right)$, Population( $\left.\mathrm{x}_{3}\right)$ and Number of Employment ( $\left.\mathrm{x}_{4}\right)$ are strongly positive relationship with Solid Waste Generation(y) with all coefficient values are more than $90 \%$. Thus, this is an evident to show that all independent variables can be used to predict the quantity of solid waste generation.

\subsection{Result of normality test}

The normality test is presented and the results are described in Table 4 and Fig. 10. The data is normally distributed when $\mathrm{p}>0.05$. As a result, solid waste generation data is normally distributed $(\mathrm{p}=$ 0.352 ) which is more than 0.05 . The skewness and kurtosis are scattered [0.307 to 0.421$]$ and [-0.831 to $0.821]$, respectively.

Table 2: Summary of descriptive statistics

\begin{tabular}{cccccc}
\hline Variables & $\mathrm{n}$ & Min & Max & Mean & Range \\
\hline GDP per capita & 31 & 9195.40 & 24847.70 & 16062.75 & 15652.30 \\
Demand of Electricity & 31 & 652.00 & 3706.00 & 2030.94 & 3054.00 \\
Population & 31 & 14256.90 & 28964.30 & 21433.86 & 14707.40 \\
Number of Employment & 31 & 5031.00 & 12284.40 & 8146.69 & 7253.40 \\
Solid Waste Generation & 31 & 206.16 & 329.99 & 259.76 & 123.83 \\
\hline
\end{tabular}




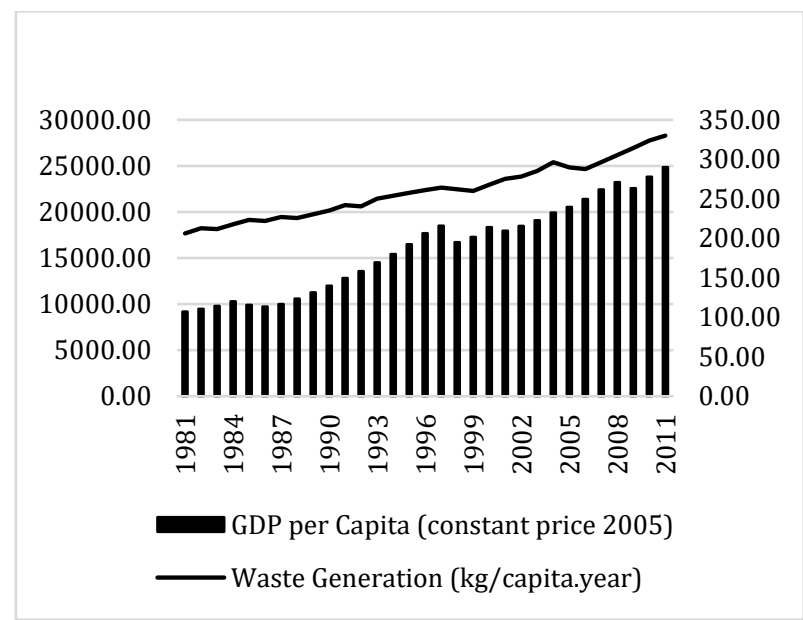

Fig. 6: GDP and solid waste generation

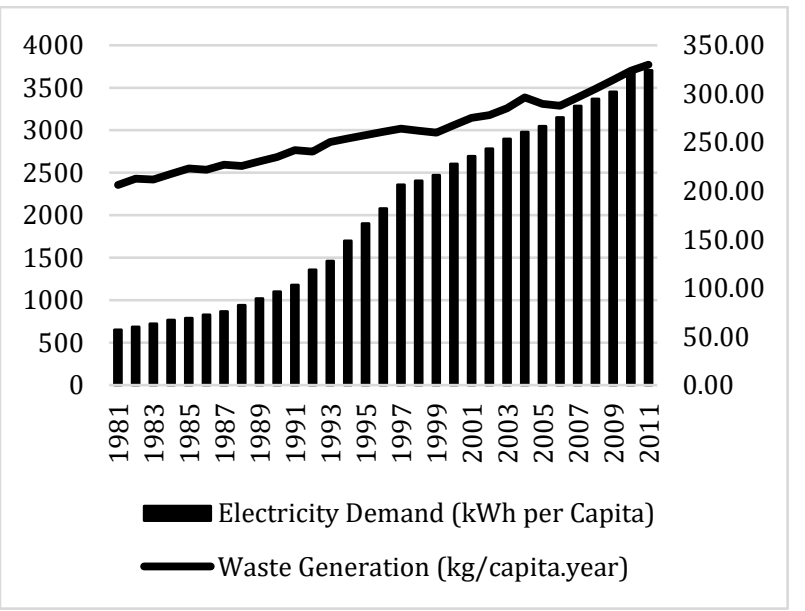

Fig. 7: Demand of electricity and solid waste generation

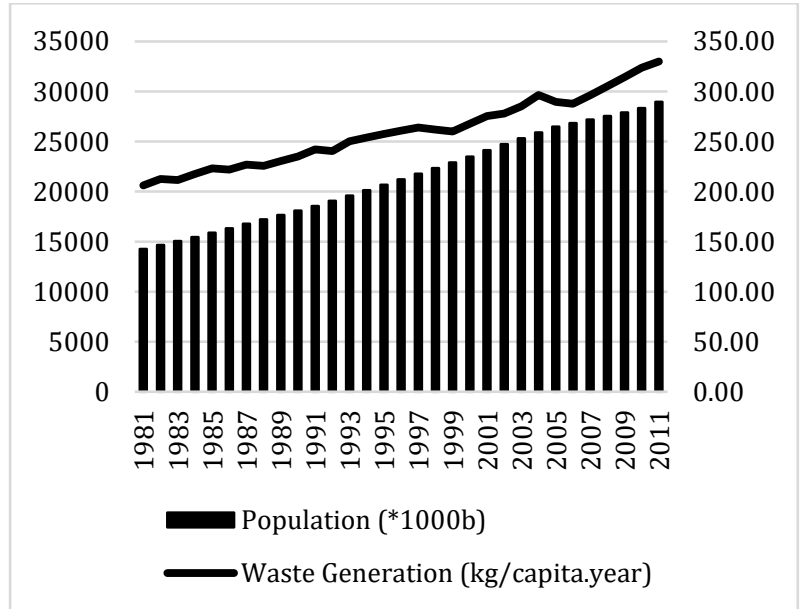

Fig. 8: Population and solid waste generation

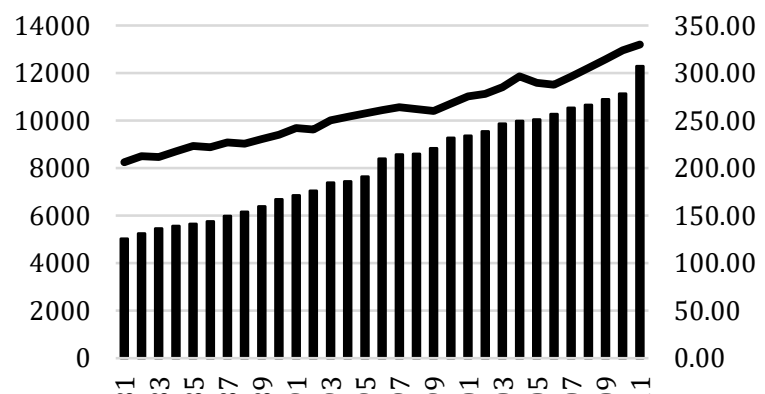

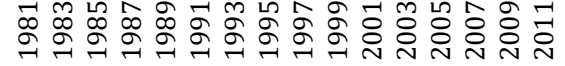

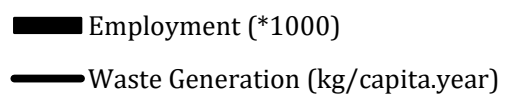

Fig. 9: Number og employment and solid waste generation

\begin{tabular}{|c|c|c|c|}
\hline Variables & $\mathrm{n}$ & Pearson Correlation & Sig. (2-tailed) \\
\hline Solid Waste Generation & 31 & 1 & \\
\hline GDP & 31 & $0.982^{* *}$ & 0.000 \\
\hline Demand of Electricity & 31 & $0.979 * *$ & 0.000 \\
\hline Population & 31 & $0.986^{* *}$ & 0.000 \\
\hline Number of Employment & 31 & $0.987 * *$ & 0.000 \\
\hline
\end{tabular}

\subsection{Results of multilinear regression analysis}

The baseline quantity of waste generation and socioeconomic factors data used for development of multilinear regression model. The multilinear regression model are shown in methodology (subsection 3.3). The results of multilinear regression model are shown below:

$S W G=b_{0 i}+b_{1 i} G D P+b_{2 i}$ Demand of Electricity + $b_{3 i}$ Population $+b_{4 i}$ Number of Employment $S W G(y)=90.794+0.003(x 1)-0.015(x 2)+$ $0.004(x 3)+0.010(x 4)$

Table 4: Normality test

\begin{tabular}{cccc}
\hline \multirow{2}{*}{ Variable } & \multicolumn{3}{c}{ Shapiro-Wilk } \\
\cline { 2 - 4 } & Statistic & $\mathrm{df}$ & Sig. \\
\hline \multirow{3}{*}{$\begin{array}{c}\text { Solid Waste } \\
\text { Generation }\end{array}$} & \multicolumn{2}{c}{ Skewness } & 0.352 \\
& \multicolumn{2}{c}{ Kurtosis } & 0.421 \\
& \multicolumn{2}{c}{-0.831} & 0.821 \\
\hline
\end{tabular}

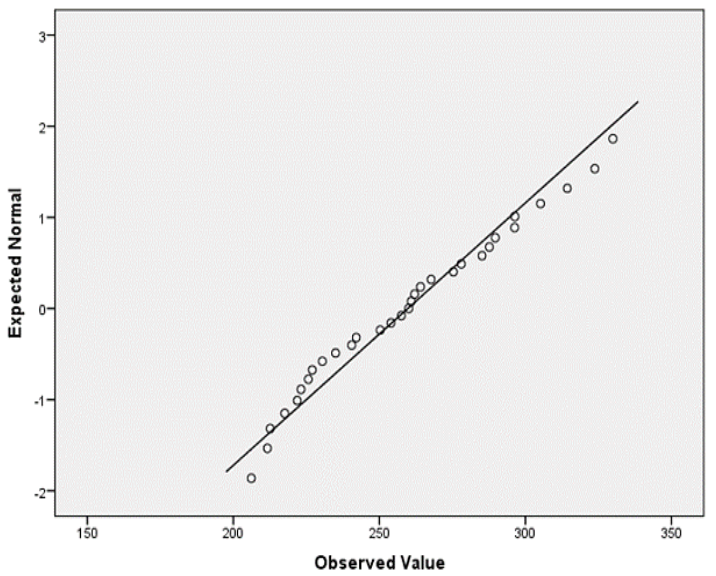

Fig. 10: Normal Q-Q plot of solid waste generation

Results of the analysis showed that the significantly the four predictor variables, namely GDP $(\beta=0384, t=1.896)$, demand of electricity $(\beta=$ $-0,448, \mathrm{t}=-1596)$, population $(\beta=0.482, \mathrm{t}=1.558)$, and number of employment $(\beta=0.573, t=1.783)$ is 
the factor to the quantity of solid waste generation in Malaysia. Overall, all predictor variables accounted for 98.9 percent $(r=0.989)$ changes in the variance in the quantity of solid waste generation.

Fig. 11 illustrates the prediction growth on solid waste generation in Malaysia for year 2012 to 2025. The quantity of solid waste generation continuously rise due to an increase in socioeconomic factors and demographic factors. As a conclusion, these prediction data is essential for waste management. It assists the management to properly establish their decision making on sustainable waste management for upcoming planning and strategies.

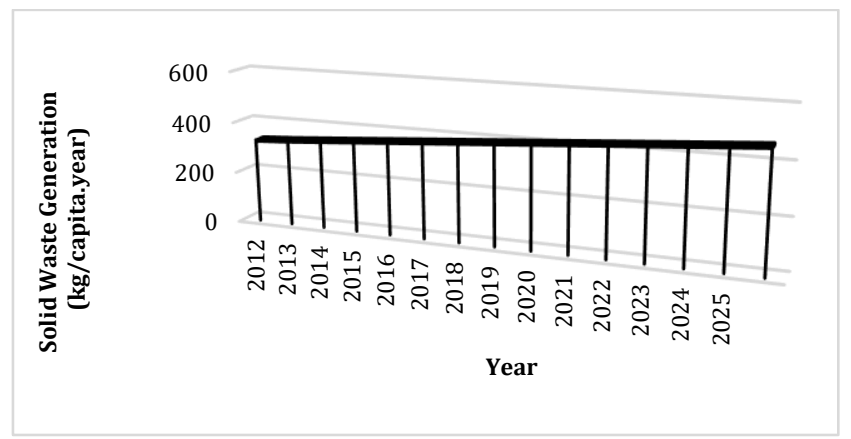

Fig. 11: Prediction of solid waste generation for year 2012-2025

\section{Conclusion}

Rapid increment in solid waste generation has raised an important environmental issue, especially for achieving the sustainable development in the Malaysia. Fast urbanization, population growth and changes in life style were identified as few of the major issues emanating from waste generation activity. Solid waste generation databases are extremely important and require urgent attention by related authorities so that the latest information is accessible. In this study, the importance of conducting prediction on solid waste generation is emphasised, which can help researchers and management in planning, decision making, and taking action for improvement. The results show strong positive linear relationships between GDP, demand of electricity, population, number of employment and solid waste generation. These results can be used as an initial data for future work, which involves developing a holistic model using the System Dynamics approach. The management of solid waste can increase effectiveness and efficiency by achieving sustainability for current and future generations and predicting the amount of waste generation. Thus, the recent positive efforts taken by the government and waste management authorities indicate a complete integrated approach in their vision planning of sustainable development, especially in solid waste management.

\section{Acknowledgment}

This study received financial support under research grant FRGS/2/2013/KT06/UKM/1.

\section{References}

Agamuthu P, Fauziah SH, Khidzir KM, and Aiza AN (2007). Sustainable waste management-Asian perspectives. In the International Conference on Sustainable Solid Waste Management, Chennai, India: 15-26.

Agamuthu P, Hamid FS, and Khidzir K (2009). Evolution of solid waste management in Malaysia: Impacts and implications of the solid waste bill, 2007. Journal Mater Cycles Waste Management, 11(2): 96-103.

Ahsan A, Alamgir M, El-Sergany MM, Shams S, Rowshon MK, and Daud NN (2014). Assessment of municipal solid waste management system in a developing country. Chinese Journal of Engineering, 2014: Article ID 561935, 11 pages. https://doi.org/10.1155/2014/561935

Alias FS, Manaf LA, and Abdullah SJH (2014). Solid waste generation and composition at water villages in Sabah, Malaysia. Polish Journal of Environmental Studies, 23(5): 1475-1481.

Andersen FM and Larsen HV (2012). FRIDA: A model for the generation and handling of solid waste in Denmark. Resources, Conservation and Recycling, 65: 47-56.

Badgie D, Samah MA, Manaf LA, and Muda AB (2012). Assessment of municipal solid waste composition in Malaysia: Management, practice and challenges. Polish Journal of Environmental Studies, 21(3): 539-547.

Begum RA, Siwar C, Pereira JJ, and Jaafar AH (2007). Implementation of waste management and minimisation in the construction industry of Malaysia. Resources, Conservation and Recycling, 51(1): 190-202.

Beigl P, Wassermann G, Schneider F, and Salhofer S (2004). Forecasting municipal solid waste generation in major European cities. In: Pahl-Wostl C, Schmidt S, and Jakeman T (Eds.), iEMSs 2004 Int. Congress: Complexity and Integrated Resources Management, Osnabrück, Germany.

Budhiarta I, Siwar C, and Basri H (2012). Current status of municipal solid waste generation in Malaysia. International Journal on Advanced Science, Engineering and Information Technology, 2(2): 129-134.

Chua KH, Sahid EJM, and Leong YP (2011). Sustainable municipal solid waste management and GHG abatement in Malaysia. In the 15th International Conference on ISO \& TQM, 04-02: 1-8..

Chung SS (2010). Projecting municipal solid waste: The case of Hong Kong SAR. Resources, Conservation and Recycling, 54(11): 759-768.

EA (2009). Perak-solid waste management plan (P-SWMP), EASWMC, EU-Asia sustainable waste management cycle. European Commission, Belgium; Luxembourg.

Ghinea C, Drăgoi EN, Comăniță ED, Gavrilescu M, Câmpean T, Curteanu S, and Gavrilescu M (2016). Forecasting municipal solid waste generation using prognostic tools and regression analysis. Journal of Environmental Management, 182: 80-93.

Mallak SK, Ishak MB, and Mohamed AF (2014). Waste minimization benefits and obstacles for solid industrial wastes in Malaysia. IOSR Journal of Environmental Science, Toxicoogy and Food Technology, 8(2): 43-52.

Marshall RE and Farahbakhsh K (2013). Systems approaches to integrated solid waste management in developing countries. Waste Management, 33(4): 988-1003.

MHLG (2006). The study on national waste minimization in Malaysia. Ministry of Housing and Local Government, Malaysia. Available online at: www.kpkt.gov.my

MHLG (2014). National strategic plan for solid waste management Malaysia. Ministry of Housing and Local Government, Malaysia. Available online at: www.kpkt.gov.my

Mohamad ZF and Keng J (2013). Opportunities and challenges in sustainable waste management transition in Malaysia: A 
multi-level socio-technical perspective. In the Globelics Seminar on Low Carbon Development. Available online at http://www.academia.edu/download/46928895/Zeeda-andKeng-2013-Malaysia.pdf

Oriola AO (2014). System dynamics modelling of waste management system. Available online at: j-sd.jp/en/2014APCProceedings/papers/P1008.pdf

Pariatamby A and Fauziah SH (2014). Sustainable 3R practice in the Asia and pacific regions: The challenges and issues. In: Pariatamby A and Tanaka M (Eds.), Municipal solid waste management in Asia and the Pacific Islands: 15-40. Environmental Science, Springer, Singapore.

Thanh NP, Matsui Y, and Fujiwara T (2010). Household solid waste generation and characteristic in a Mekong Delta city, Vietnam. Journal of Environmental Management, 91(11): 2307-2321.

Younes MK, Basri NEA, Nopiah ZM, Basri H, Abushammala MF, and Maulud KNA (2015). Integrating approach to size and site at a sanitary landfill in Selangor state, Malaysia. Environmental Engineering Research, 20(3): 268-276. 